Article

\title{
Art in the Age of Social Media: Interaction Behavior Analysis of Instagram Art Accounts
}

\author{
Xin Kang ${ }^{1, * \mathbb{D}}$, Wenyin Chen ${ }^{1}$ and Jian Kang ${ }^{2}$ \\ College of Design, National Taipei University of Technology, Taipei 10608, Taiwan; wychen@ntut.edu.tw \\ 2 Xindi Energy Engineering Technology Co., LTD, Langfang 065001, China; kangjiana@enn.cn \\ * Correspondence: kangxin@pku.edu.cn
}

Received: 29 October 2019; Accepted: 3 December 2019; Published: 7 December 2019

\begin{abstract}
Instagram is the top preferred social media platform in the art world, however, we know little about the features of the most-liked artworks, and what role does the interaction between artists and followers play in the most-liked artworks? This study used quantitative and qualitative methods to examine the interaction between artists and followers on Instagram and the features of the most-liked artworks. Data from 706 artists' accounts 497,649 posts on Instagram and 35 questionnaires. The results reveal that likes and comments were greatly influenced by interactions, with confusion and curiosity being a big reason to engage. The artist's life experience and interaction with the followers had a positive influence on the most-liked artworks. Interaction with followers does not have much impact on their artistic creation, although artists expect more likes. Our study expands the research of mobile social media interaction in the art world, which is of great significance for the research on the interactive psychology of artwork and digital marketing communications on social media. The findings can also support future research on citizen curators and sociology analytics research areas.
\end{abstract}

Keywords: Instagram; social media; interaction; artwork; like; participation

\section{Introduction}

With the rise of online artwork trading, understanding what kinds of artworks drive participation is crucial. However, little research has focused on the relationship between artworks and interactions on social media. What does the popularity of an artwork depends on? We're at a crossroads where the traditional physical art experience is migrating toward a more web-based environment. The online art market has increased substantially from the past five years (by 72\%) [1], with more than 71 percent of art collectors has purchased some form of art online last year [1]. Art goes into the age of social media [2]. Instagram has the highest engagement rates of all the social media platforms, $48 \%$ of art buyers using Instagram [3]. Museums' communication has been redefined too [4-6], the relationship between museums and the public is changing towards more interactive and collaborative forms $[4,7,8]$. Social media is increasingly being used directly to create or plan art. Frye held an exhibition of the "most-liked" paintings, which were voted for by nearly 4,500 people on different social media platforms [9].

Media ecology believes that media is the extension of human senses of every era, and the main reason for social change is communication technology [10]. Digital participation deepens and democratizes artistic exchange with audiences [11], it has changed the role of the audience, and blurred boundaries of concepts such as "professional" and "public" [12]. Before the age of the Internet, art critics determine the value of art. Today, Instagram is an extraordinary way to discover, promote and critique art [13]. "Instagramism" as the aesthetic of the new global digital youth classes that emerge in the early 2010s [14]. The online art experiences make all kinds of artworks to be adjusted 
in a highly interactive process. Many museums use "citizen curators" and "user-generated content" to plan exhibitions [15]. For example, the Brooklyn Museum, inspired by James Surowiecki's book The Wisdom of Crowds, staged an exhibition titled "Click!", based on feedback from museum visitors and online voters ranked entire artworks [16].

McLuhan argues that media is the extensions of human [17], interactivity is the typical feature of the Internet [18]. Tom Valcanis believes that if the technology is a medium of cultural development, the interaction and user orientation of these technologies had produced a participatory "mashup" cultures. The ways of generating and accessing content are deconstructed by online platforms, computers and smartphones, and online content is uploaded, mixed, fused and reconstructed [19], forming a "participatory culture" [19]. Participatory culture is a culture with relatively low barriers to artistic expression and civic engagement, strong support for creating and sharing one's creations, and some type of informal mentorship whereby the most experienced people pass along what they know to novices. A participatory culture is also one in which members believe their contributions matter, and feel some degree of social connection with one another [20]. Likes and comments are the most pervasive, and fundamental levels of participation [21]. The interactions on social media occur very rapidly, which can be understood as a novelty or moment effect. The audience interacts with an artwork in seconds or even less with intuition.

\subsection{Research Questions}

Art experience on social media has been a major shift, understanding what kind of artworks drive participation is crucial. Most previous studies have demonstrated the impact of mass participation on social media using experiments, text or photographs, including box office [22], dance [11], music [23], photography [24], fashion [25], personality [26] and social impact assessment [27], etc. However, the relationship between artworks and interaction on social media is still a new research area, limited works in this field had been published, especially for assessing visual artworks, we did not find any previous work on it. To this end, we conduct both quantitative and qualitative analysis to examine what is the relationship between the most-liked artworks and interaction, and will the interaction between artists and followers affect their artistic creation?

The general aim of this paper is set up in six research questions (RQs) out of two studies, the first four of which are related to the feature of the most-liked artwork, and the last two of which are related to the impact of interaction on artists:

Study1:

- RQ1: What kind of artwork gets the most likes and comments?

- RQ2: What makes people press the "like" button and comment on the artwork?

- RQ3: What is the relationship between interactions, likes and comments?

- RQ4: Are female artists more popular?

Study 2:

- RQ5: Do the most-liked artwork also the best artworks considered by the artist?

- RQ6: Do the most-liked artwork influence the artist's creation?

Instagram is redefining the way the art world does business. It might be a perfect time to study online art interactivity on Instagram. The theoretical contribution of this study is to expand the research of social media users' interactive behaviors in the art market, which is of great significance of studying the art psychology and marketing communication in the era of mobile internet. Moreover, we believe that our analysis reveals important psychological aspects that are beyond the artwork scope, which provided valuable material to the future research on citizen curators, sociology analytics research areas. To the best of our knowledge, we believe this is the first systematic analysis of the most-liked artworks and interactions on Instagram. 


\subsection{Definitions of Key Terms}

\subsubsection{Artwork}

The term "artwork" we are discussing here is visual arts, which includes such as drawing, painting, sculpture, architecture, photography, film, and printmaking, etc. [28]. The influence of digital technology has transformed the traditional visual arts. New media art refers to artworks created with new media technologies, including digital art, computer graphics, computer animation, virtual art, Internet art, interactive art, video games, computer robotics, 3D printing, cyborg art and art as biotechnology [29].

\subsubsection{Self-Actualization}

Self-actualization was originally introduced by Kurt Goldstein for the motive to realize one's full potential [30]. Abraham Maslow believed that actualization was the driving force of human personality, he achieved five levels of motivation: physiological, safety, social, esteem, and self-actualization [31]. Maslow stated that human motivation is based on people seeking fulfillment and change into personal growth.

\section{Theoretical Background}

Interaction plays an important role in social media, Ritter pointed out that although form and content are extremely significant to the creation of art, consideration can also be given to the method of communication between the artwork and a person [32]. The relationship between museums and mass is changing towards more interactive and collaborative forms $[4,6,33]$. The changing functions of the museum and the role of the curator might indeed change the very role of art in society as well. Digital technologies have played a crucial role in expanding the boundaries of art, social media has changed the expectations of audiences, and even the notion of art is changing [34]. Digital interaction with the audience can promote cognitive decoding and enhance kinesthetic and emotional responses to artistic activities [11]. A variety of simple graphical filters are available to camera phone users to enhance their photos, filtered photos are $21 \%$ more likely to be viewed and $45 \%$ more likely to be commented on by consumers of photographs [24]. Manovich's book Instagram and Contemporary Image, places Instagram image culture within a rich cultural and historical context, including histories of photography, cinema, graphic design, as well as contemporary social media, design trends, music video, and k-pop. Manovich uses Instagram as a window into the identities of a young global generation connected by common social media platforms, cultural sensibilities, and visual aesthetics [14]. Social media is redefining the art world, influencing not only the marketing but also the creation and curation of art [9].

Social media feeds people's social, esteem and Self-actualization needs [31]. Most sites help strangers connect based on common interests, political views, or activities that inspire people to participate [35]. Instagram users have five primary social and psychological motives: social interaction, archive, self-expression, escapism, and peeking [36]. Self-expression is achieving personal goals, present a consistent and positive view of ourselves to the world and conform to social norms [37]. Erving Goffman believes that the motivation for self-presentation is to receive positive feedback and meet the expectations of others [38]. Amy Jo Kim put forward Maslow's hierarchy of needs in the online community, the ability to self-realize is to assume the role of the community, develop skills and open up new opportunities [39]. Zhu and Chen analyzed in detail how different types of social media services fulfilled human needs [40]. Sheldon, Elliot, Kim, and Kasser discussed the most basic psychological needs of human beings are: autonomy, competence, relatedness, and self-esteem [41]. People seek self-expression, self-esteem, and self-actualization through social media engagement.

Social media is a demanding area that requires constant engagement and status updates from its users. Nancy K. Baym came up with the concept of "relational labor" of social media connection [42]. According to a survey by the Pew Research Center, 34 percent of social media users admitted to using social media to "take a mental break", 27 percent used social media to keep in touch with their families and 24 percent established or supported professional contacts [43]. The main reasons for Instagram use are surveillance, 
documentation, coolness, and creativity, interpersonal interaction and narcissism are positively related to most motives for Instagram use. Gender is the best predictor of the Instagram use [44].

The study of the user-generated content of social media reflects many aspects of society. Hochman and Schwartz analyzed a dataset of over half a million photos taken in New York and Tokyo and used visualization techniques in an attempt to highlight cultural differences [45]. Social media can be an effective mechanism for cultural diffusion [46]. Styles and trends are easily conveyed online to attract trendsetters [47]. Kavita Bala and Noah Snavely came up with a framework for visual discovery at scale, by analyzing clothing and fashion in images of millions of people around the world [48]. Hu, Manikonda, and Kambhampati argue that a strong social media presence may be more important than being under contract with a top agency, or than the aesthetic standards sought after by the industry [49]. Hamari, Sjoklint, and Ukkonen believes that the importance or usefulness of contents and services is exclusively defined not just by the organization producing it, but by the public using them. [50]. Kang and Chen first studied the relation between artists and followers [51]. Social media gives artists the ability to control the way their story is told, and find people who want to hear it, feeling as if you know the artist. To what extent does the content released by artists and the interaction with followers affects the likes of artworks? If the quality of artworks is not completely defined by artists or organizations, to what extent should we trust the wisdom of crowds? Do the likes and comments on the artwork have anything to do with the quality of the art? This study will provide new insights into the nature of artwork interactions driven by social media.

\section{Methodology}

In this section, we describe in detail how to collect data to illustrate our statistical approach and analysis process.

When the users posting on social media, the content should be impactful, and a good way to assess impact is by looking at the interactions that posts get. We chose the number of likes, comments, posts, followers and followings as the features that represent fundamental aspects of engagement on Instagram. We used quantitative and qualitative research methods to systematically study the interaction between artists and followers on social media. Study 1 investigates the features and reasons for the mass most-liked artwork (RQ1, RQ2, RQ3, and RQ4), and study 2 investigate the artist's view of interaction (RQ5 and RQ6).

\subsection{Study 1}

We randomly selected 1000 visual art individual accounts with more than 10,000 followers on Instagram (The selection of artists with more than 10,000 followers is to ensure that the users we choose are popular artists, so as to analyze the popularity of their works), based on the users' bio, after eliminating the company or promotion accounts, we manually identified 706 visual art artists. It is guaranteed that our dataset is composed of popular and ordinary Instagram artists.

The dataset we are collected includes (1) profile information, photos, captions and tags associated with photos, and users' social network that includes followers, and followings; (2) biography; (3) posts (artwork images or videos); (4) likes, comments and tags, etc. (see Figure 1).

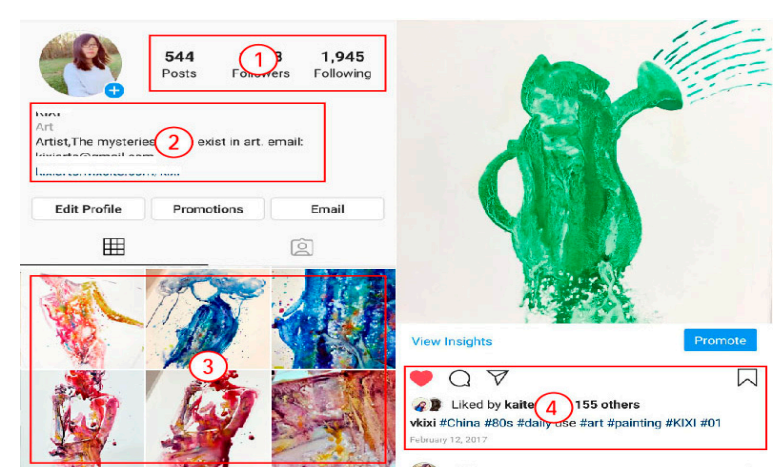

Figure 1. The data we collected on Instagram. 
First, we visited all users' Instagram pages and checked their profile image, bios descriptions or personal website, manually verified the artists' gender, country, and art forms. The final data set includes 497, 649 posts of 706 artists (319 males and 387 females) in 48 countries, and the value of posts, likes, followers, followings and comments (see Table 1).

Table 1. Descriptive statistics.

\begin{tabular}{cccccc}
\hline & Frequency & Percent & Valid Percent & Cumulative Percent \\
\hline Male & 319 & 45.2 & 45.2 & 45.2 \\
Female & 387 & 54.8 & 54.8 & 100.0 \\
Total & 706 & & 100.0 & 100.0 & \\
& $N$ & Minimum & Maximum & Mean & $\begin{array}{c}\text { Std. } \\
\text { Deviation }\end{array}$ \\
\hline Followers & 706 & 433 & $2,146,849$ & $92,914.61$ & $186,406.308$ \\
Followings & 706 & 1 & 7499 & 876.17 & 1141.704 \\
Posts & 706 & 14 & 10,927 & 704.89 & 867.539 \\
Likes & 706 & 101 & 362,297 & $11,080.65$ & $25,491.960$ \\
Comments & 706 & 2 & 21,911 & 179.02 & 997.674 \\
Valid N (listwise) & 706 & & & & \\
\hline
\end{tabular}

Second, we classified the artworks of 706 artists to analyze what kind of artworks were the most popular. However, the art classification has many ways, which can be classified by media, by content or by genre, different websites or social media platforms are classified differently. For example, WikiArt classifies artworks as 61 categories by genre and 185 categories by media [52]. Besides, many traditional disciplines are now integrating digital technologies, the lines between traditional works of art and new media works created using computers have been blurred. On social media, hashtags are a great way to get your post found. Bourdieu, Darbel and Schnapper believe that it is appropriate to define art from the audiences' perspective [53]. In the end, we combined the definition of visual art with the popular art hashtags on Instagram, dividing the collection of three categories (see Table 2).

Popular art hashtags on Instagram:

- \#painting (\#oilpainting, \#watercolorpainting, \#watercolors, and \#acrylicpainting, etc.)

- \#Illustration (\#cartoonist, \#cartooning, \#cartoonart, \#comicstyle, and \#indiecomic, etc.)

- \#digitalpainting (\#digitalart, \#digitalart, \#characterdesign, \#digitaldrawing, \#animation, and \#gameart, etc.)

Table 2. The frequency of the three categories on Instagram.

\begin{tabular}{cccccccc}
\hline & Frequency & Followers & Following & Posts & Likes & Comments & Percent \\
\hline \#Painting & 519 & $46,606,438$ & 481,383 & 379,395 & $5,200,716$ & 88,759 & 73 \\
\#Digitalpainting & 35 & $3,181,762$ & 19,509 & 19,421 & 472,168 & 4312 & 22 \\
\#Illustration & 152 & $15,809,518$ & 117,683 & 98,833 & $2,150,053$ & 33,314 & 5 \\
\hline
\end{tabular}

Third, we ranked all the posts of 706 artists by likes and comments separately and then conducted a qualitative analysis of the top 10 liked and the top 10 commented to see what kind of artworks are more popular and why.

\subsection{Study 2}

We administered an online questionnaire to explore the interaction influencing artists in multiple variables. Thirty-five artists completed the questionnaire on Instagram (males 15, 43\%; females 20, $57 \%$ ), aged from 20 to $65+.60 \%$ of the artists had been an artist for more than 10 years. Among them, $48 \%$ of the participants are college graduated, $26 \%$ are post-graduated, $11 \%$ are high school graduated, 
$9 \%$ are graduated from some college and $6 \%$ are trade/technical/vocational training (see Table 3 ). The participants are from 15 countries, 37\% were from US, 17\% were from UK, 6\% were from Canada, 5\% were from Australia and China, with 3\% from Denmark, France, German, India, Japan, Philippines, Russia, Saint-Gilles les Bains, Singapore, and Turkey.

Table 3. Descriptive statistics.

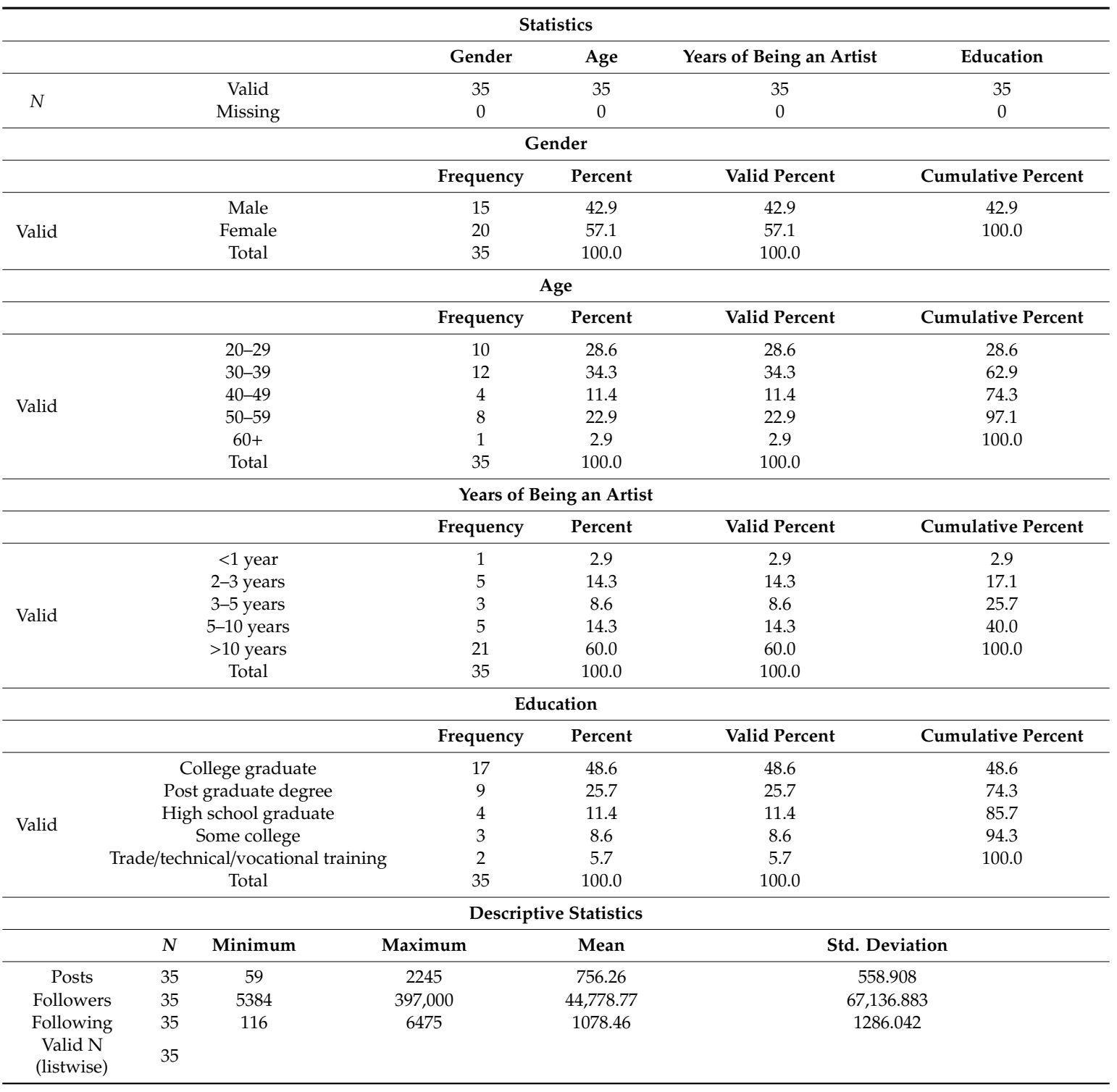

\section{Data Analysis and Results}

In this section, we describe the finding of users' practices on Instagram obtained by analyzing the above data we collected.

\subsection{Findings of Study 1}

First of all, we want to figure out if a particular type of artwork is more popular, we conducted an analysis of variance (ANOVA) on the three categories of artwork. The results show that: $p=0.094,>0.05$, which means that there is no statistically significant difference, indicating that the people have no particular preference for a certain category of artwork (see Table 4). 
Table 4. The one-way analysis of variance (ANOVA) of the three categories of artwork.

\begin{tabular}{cccccc}
\hline \multicolumn{5}{c}{ ANOVA } \\
\hline \multicolumn{5}{c}{ Likes } \\
\hline Sum of Squares & df & Mean Square & F & Sig. \\
Between Groups & $1.819 \times 10^{9}$ & 1 & $1.819 \times 10^{9}$ & 2.806 & 0.094 \\
Within Groups & $4.563 \times 10^{11}$ & 704 & $6.482 \times 10^{8}$ & & \\
Total & $4.581 \times 10^{11}$ & 705 & & & \\
\hline
\end{tabular}

Secondly, we use the k-means cluster to generate the corresponding user cluster. Based on the value of posts, likes, comments, followers, and followings, we perform the clustering multiple times to determine the best $\mathrm{k}$ (the number of clusters) with root mean square error is minimized. The 706 artists can be divided into three clusters (see Table 5).

Table 5. Cluster analyses of the 706 artists.

\begin{tabular}{cccc}
\hline \multicolumn{3}{c}{ Number of Cases in each Cluster } \\
\hline \multirow{3}{*}{ Cluster } & 1 & 654.000 \\
& 2 & 6.000 \\
& 3 & 46.000 \\
& Valid & & 706.000 \\
& Missing & 0.000 \\
\hline \multicolumn{4}{c}{ Final Cluster Centers } \\
\hline \multicolumn{3}{c}{ Cluster } \\
\cline { 2 - 4 } Followers & 1 & 2 & 3 \\
Followings & 54,535 & $1,638,814$ & 436,939 \\
Posts & 901 & 328 & 601 \\
Likes & 662 & 1134 & 1265 \\
Comments & 6481 & 195,449 & 52,430 \\
& 84 & 2166 & 1270 \\
\hline
\end{tabular}

Cluster 1 is the largest category, with 654 artists (91\%) and the most following number, and the fewest followers, posts, comments, and likes. Cluster 2 is the smallest category, with only six artists $(1 \%)$. However, the followers, likes, and comments are the most, the number of posts of the second and the followings amount is the least. In Cluster 3, the second-largest category is 46 artists (6\%), with the most posts, and the second followers, followings, likes, and comments.

Cluster $2(1 \%)$ is famous artist or celebrity who usually pays little attention to other users but has high quality followers and comments. The celebrity effect is a typical halo effect, which tends to judge a person as good in many ways because it is widely believed [54]. Most artists belong to Cluster 1 $(91 \%)$ and Cluster $3(46 \%)$. Users with a medium number of followers usually have almost the same number of followings.

In order to get the features of the most popular artworks, we qualitatively analyzed the content and text of the top 10 most-liked and most-commented artworks respectively. The results show that photos of the artist's face and their artwork or posts about the artist's working process generally received more likes. Photo with face attracts more likes and comments on Instagram [55]. Facial attraction is based on universal (inborn) perceptual mechanisms and cultural influences. The perceptual mechanisms of facial attractiveness and beauty in artworks follow a similar ontogenetic pattern. Evidently, face attractiveness is relevant to mate selection, as is the beauty of the human body [56]. Faces are powerful channels of nonverbal communication [57]. The faces provide vital clues to an impressive variety of contexts: attraction, the complexity of emotions, identity, age, humor, a person's regional and national background [58]. Age and gender have been studied extensively as factors affecting social media use, but female artists have not shown a more popular side. The top 10 posts include tutorials, illustrations, 
share artist life, or interesting comic; the first most-liked post is a tutorial video. Some of the most common words of the comments are: Wow! What is this?; Love; Awesome; Mind-blowing; etc. The most common reasons for comments are curiosity, ask questions and approval.

\subsubsection{The Most-Liked Artworks}

In this section, we make a detailed analysis of the most-liked artworks and the most-commented artworks respectively based on the posts' titles, comments, and text contents.

Figure 2 shows the log-log plot of the correlation between the followers and the likes of the 706 artists. The larger circles indicate more likes, and the darker circles show more followers. Obviously, there are two extreme values: No.555 and No.36. According to the like equation, we can predict the popularity of one artist in the future.

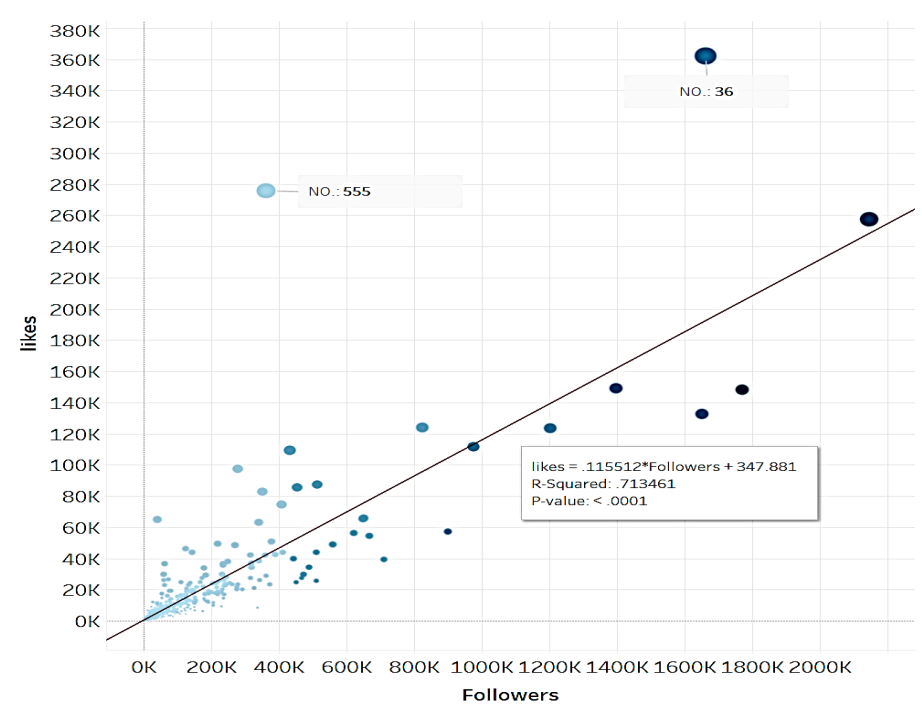

Figure 2. Correlations on Instagram, followers vs. likes.

Equation: likes $=0.115512 \times$ Followers +347.881 ; R-Squared: $0.713461 ; p$-value: $<0.0001$. Likes and followers have a significant correlation.

The post of the extreme value of No.36 got 377,707 likes and 6591 comments. The No.36 artist is an illustrator and a professional doodler, the most-liked post's caption is: "Don't vs Do". It is a tutorial video of painting, in which the artist discusses the experience of painting with the followers. The other extreme values of No.555 which got 273,754 likes and 2135 comments, it is a humorous illustration. Comments show that the reason for clicking the "like" button is interesting and curious (see Figure 3).

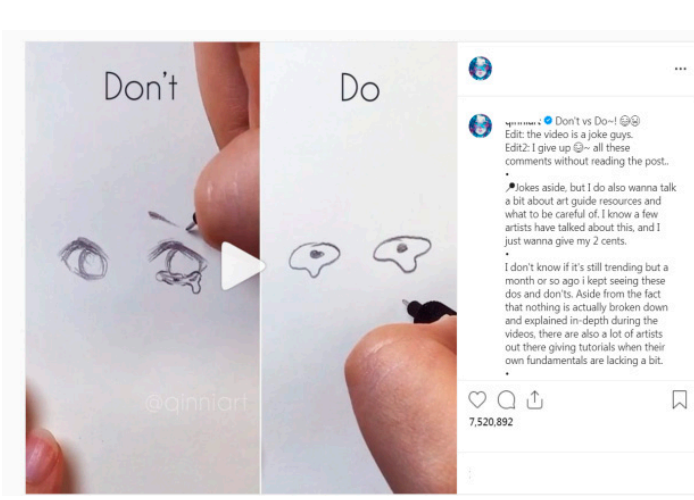

(a) No. 36

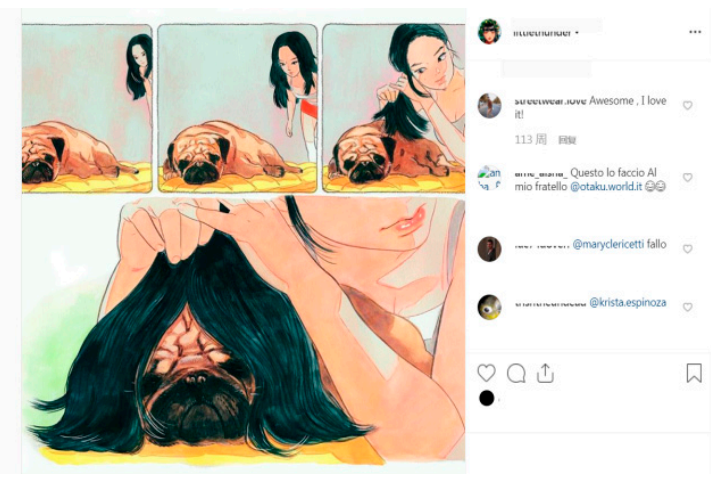

(b) No. 555

Figure 3. Screenshots of the two extreme values (shared by @qinniart and @littlethunder). 
Figures 4 and 5 show the likes and comments growth of the artist No.36 and No.555. The comments change little with the growth of likes. For further analysis, we collected the top 10 liked posts of these two accounts.

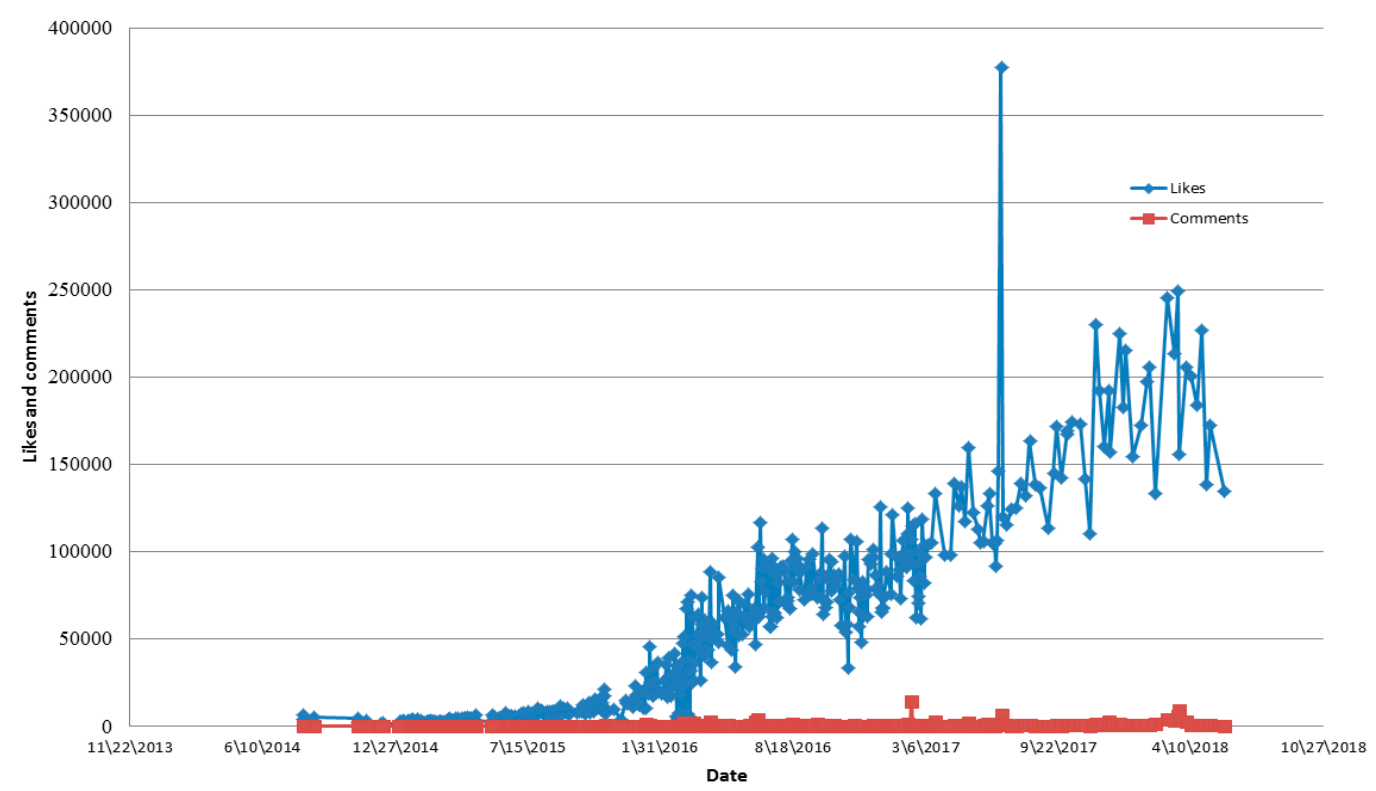

Figure 4. Account No.36596 posts' likes and comments growth of 5 years.

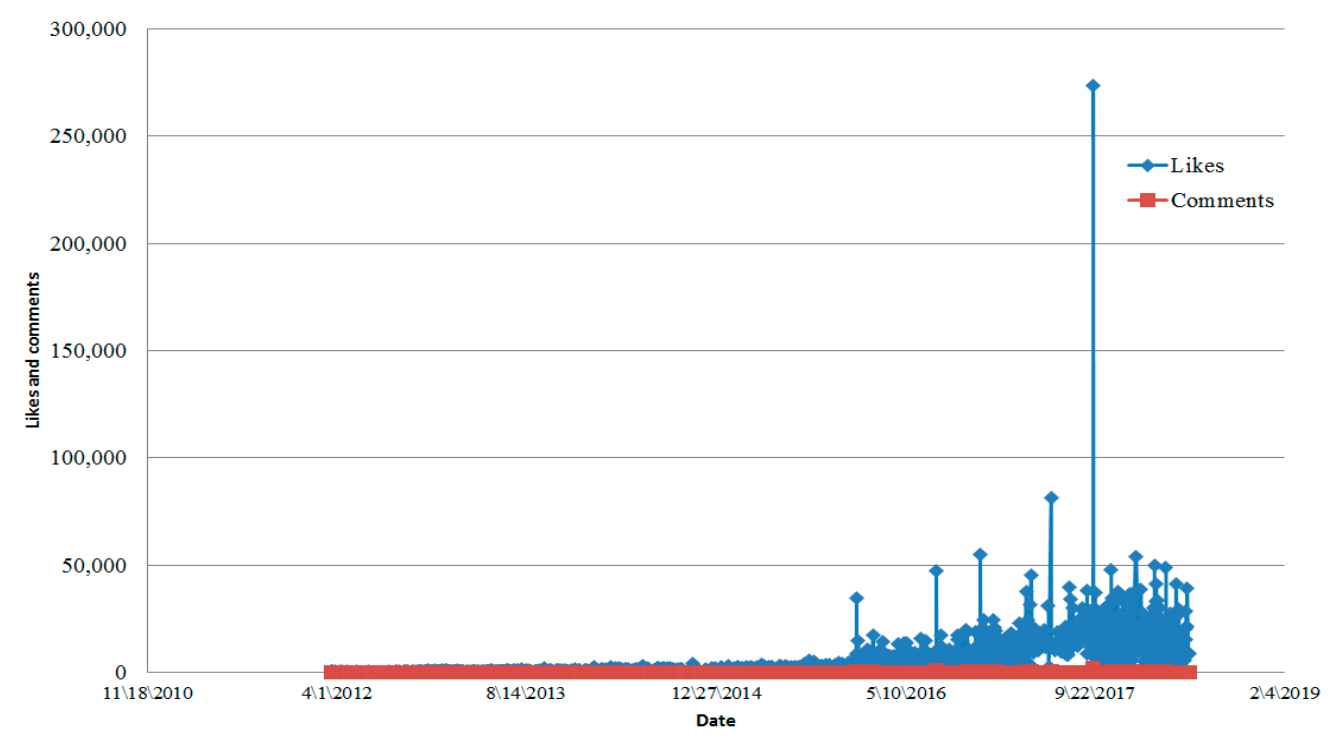

Figure 5. Account No.5552047 posts' likes and comments growth of 5 years.

The artist No.36's top 10 most-liked posts shared illustrations of her own disease development, which caused a lot of resonance. The top most-liked 10 posts by No.555 have four videos shown the artist painting progress, and the other images are very interesting comics.

\subsubsection{The Most-Commented Artworks}

Figure 6 shows the trend of comments and likes of the 706 artists' accounts. The bigger the diamond and the darker the color, the more people like it. Obviously, the figure shows two extreme values: No.310 and No.558. 


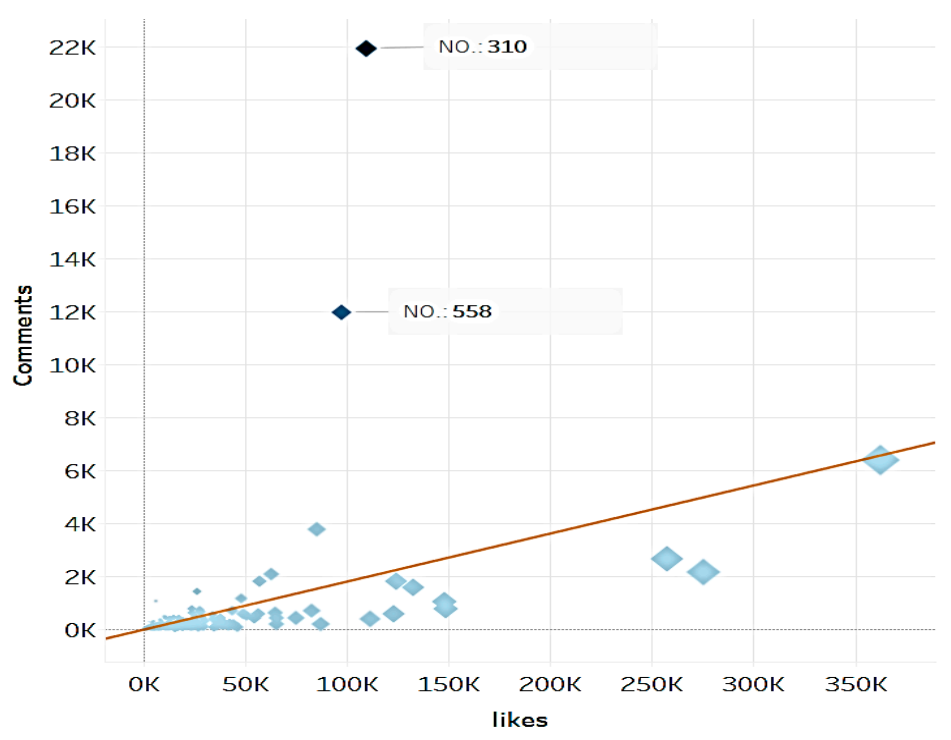

Figure 6. Correlations on Instagram, comments vs. likes.

Equation: Comments $=0.0181489 \times$ likes $+-22.0862 ;$ R-Squared: $0.215046 ; p$-value: $<0.0001$. Likes and comments have a significant correlation, which is has been verified in Kang and Chen's research [52].

We analyzed the two extreme values in detail, No.558 got 100,160 likes and 12,211 comments. This post's caption is talking to the followers on which one is better and encourages them to comment. The No.310 extreme value got 108,587 likes and 21,708 comments. The main comments are curiosity, doubt and strange (see Figure 7).

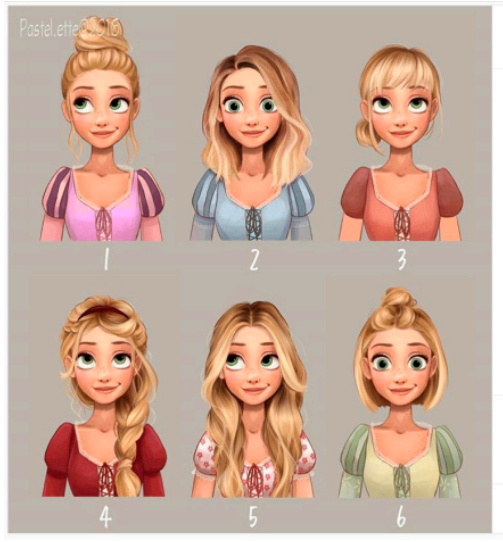

(a) No. 558

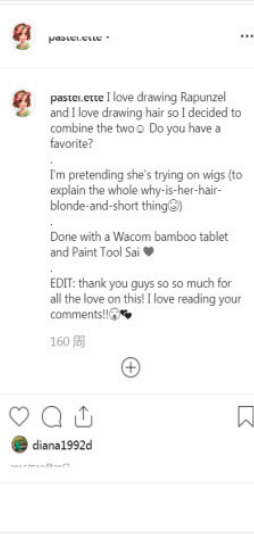

ロ

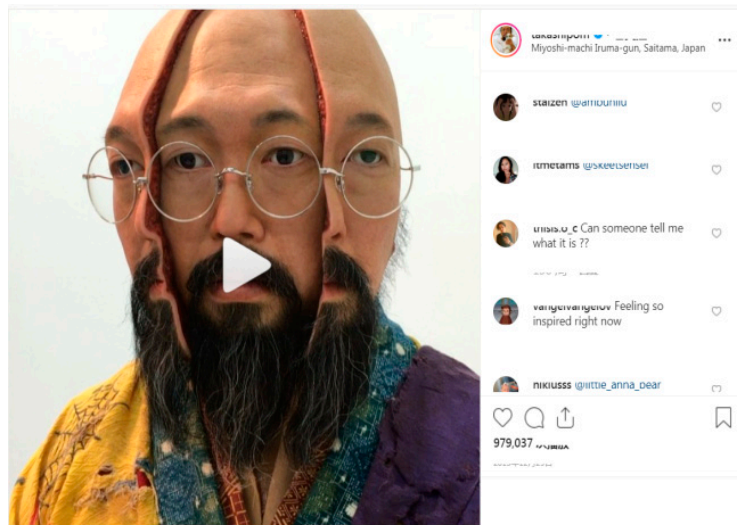

(b) No. 310

Figure 7. Screenshot of the extreme value of No.558 and No.310 (Shared by @ pastel.ette and @takashipom).

The obvious common feature of the top 10 most-commented posts by No.558 is asking a question: "Do you have a favorite?". No.310 is a famous artist, who keeps sharing his new artwork and art activities on Instagram. As similar to other social media, celebrities are the top users in terms of followers and most of them do not follow their followers back.

Figures 8 and 9 shows the growth of likes and comments on account No. 558 and No. 310 respectively. It shows that comments do not change much with the growth of likes. For further analysis, we collected the top 10 liked posts of all posts of these two accounts. 


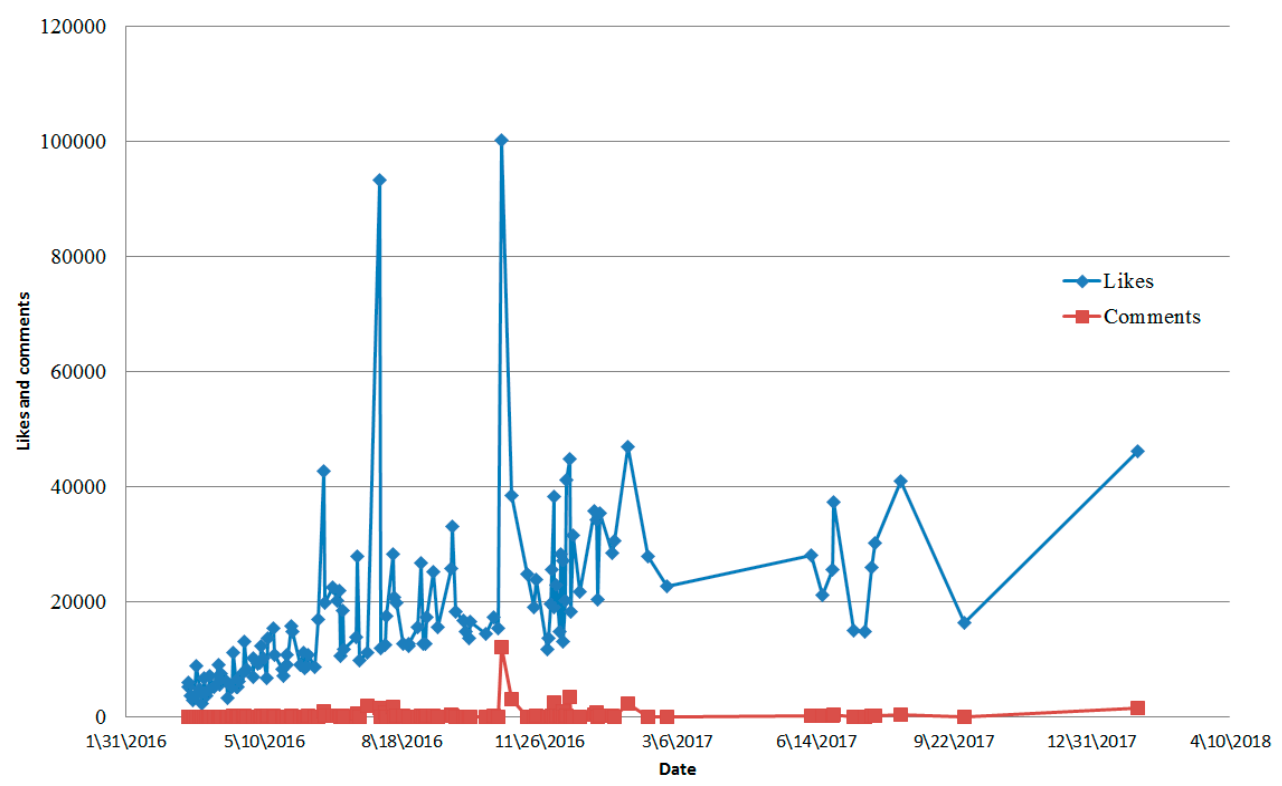

Figure 8. Account No.558132 posts' likes and comments growth of 3 years.

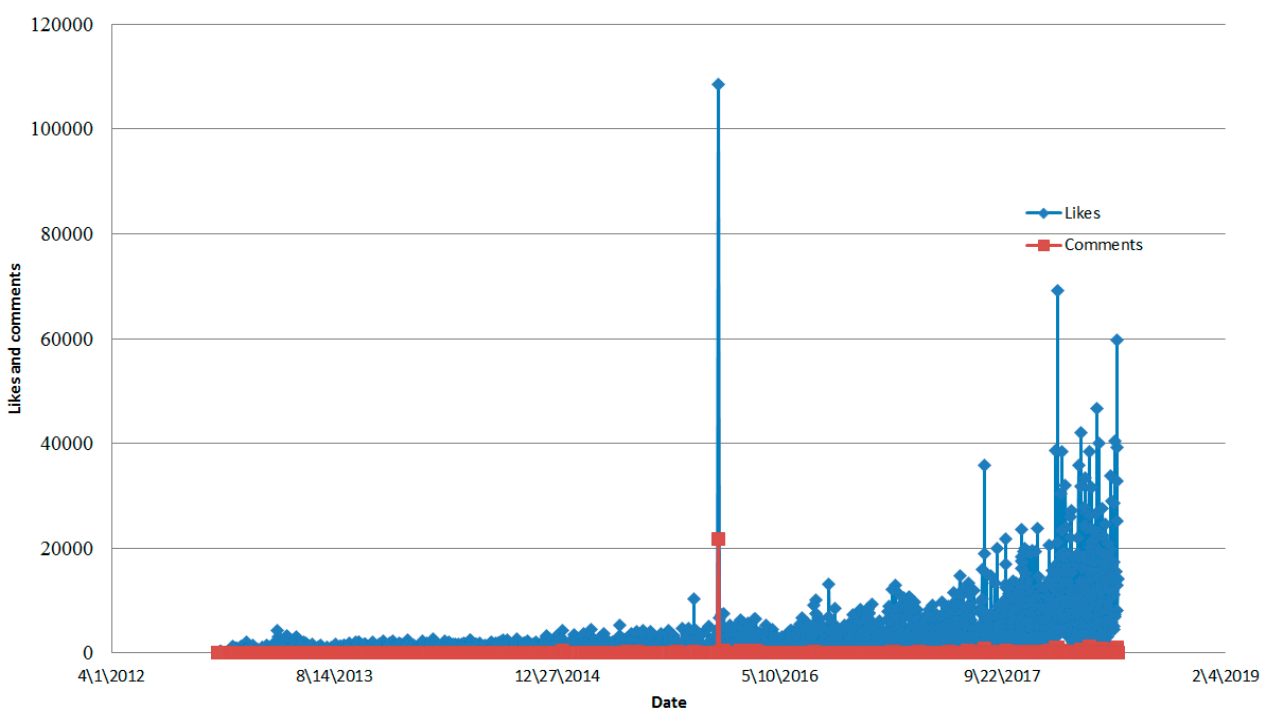

Figure 9. Account No.3106751 posts' likes and comments growth of 6 years.

In order to analyze the impact of interaction on likes and comments to get the features of the most popular artworks, we sorted each artist's data based on the number of likes and comments and qualitatively analyzed the captions and comments of the most-liked and most-commented posts.

Figure 10 shows the top 4 most-commented posts by artist No.558. The artist always asks their followers questions about her paintings, which causes a lot of discussion with her followers. Some of the most-commented posts' captions are: "Do you have a favorite hairstyle or outfit?", "Help! I can't decide on the color of her dress! Which one do you like most?", "Which one do you prefer?". The artist No.558 has posted only 132 posts in three years, all of which are featured rapid growth of likes and comments by asking questions. 

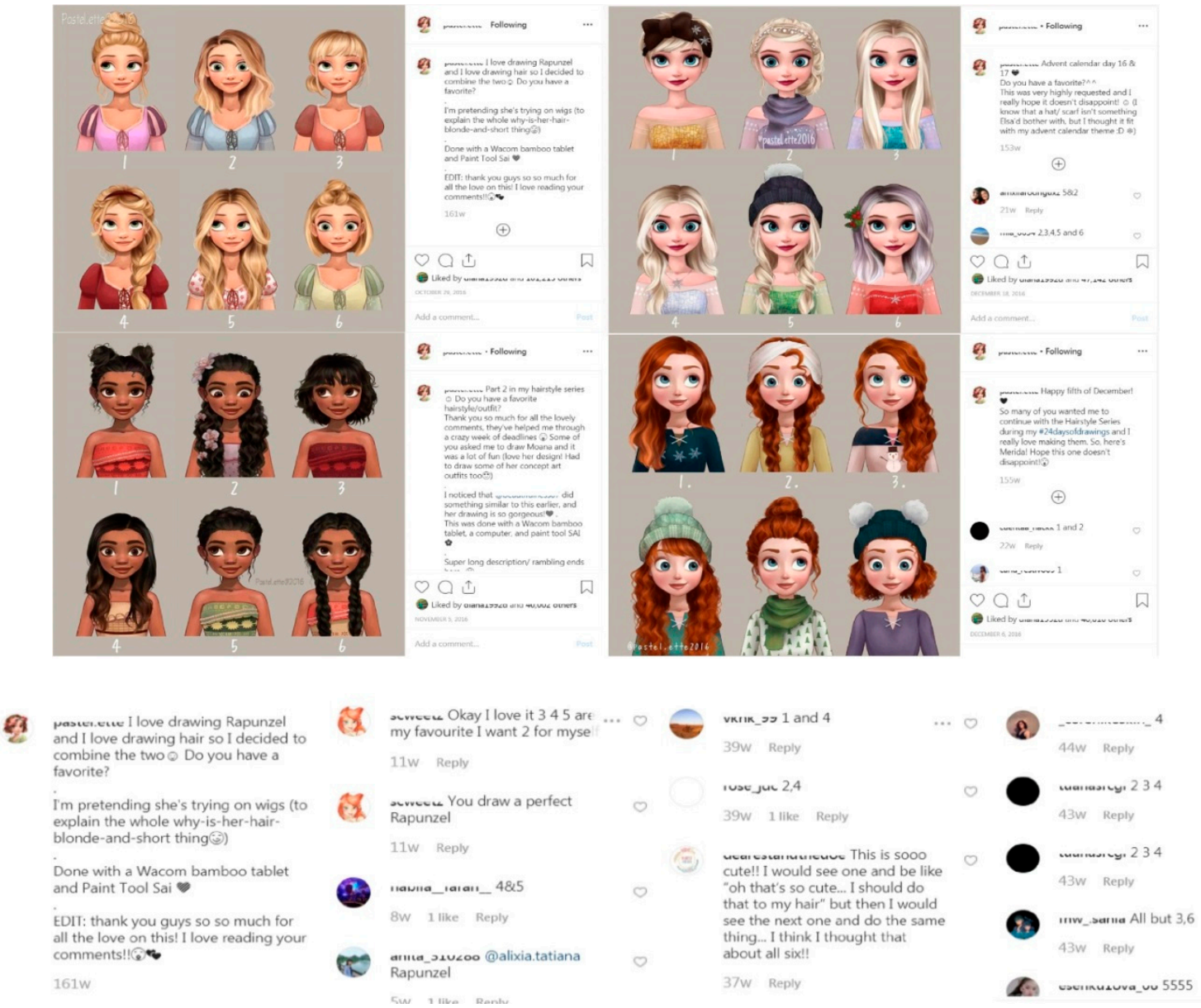

Figure 10. Screenshot of the top 4 most-commented posts and one of one posts' comments (Shared by @pastel.ette).

\subsection{Discussion 1}

We analyzed the four abnormal values of Figures 2 and 6 (No.36, No.555, No.310 and No.558) as well as the growing status of likes and comments, and found that some common features of these popular posts contents, including sharing tutorials, sharing painting process, interesting or humorous illustrations, empathy, asking questions, curiosity, and celebrity, etc., we divide it into the following categories:

- $\quad$ Practical information sharing (sharing tutorials or painting process);

- Ask a question: "what do you think?";

- Arouse curiosity: "what is this?";

- Interesting or humorous illustration;

- Empathy.

The common feature of the most-liked and most-commented artworks is the deep exchange and interaction with followers by asking questions or displaying their art and personal lives. The audience feels that they are the artist's friends and participate in the artist's life and creation. Participation in social media, as Jenkins said, is a culture in which members believe that their contributions are important and express their value through communication with artists so as to grow together with artists. Traditional art experience is interpreted by experts or organizations, which is passive and didactic. Social media has shaped the new art experience online, and the real-time communication between artists and audiences allows all kinds of artworks to be adjusted at any time in a highly 
interactive process. The audience unconsciously participates in the selection of artworks by likes and comments.

Human beings are intuitive thinkers, and these common features of the popular posts mentioned above reflecting Abraham Maslow's view that the driving force of human personality is self-actualization [31]. He achieved five levels of motivation: physiological, safety, social, esteem, and self-actualization [31]. Users achieve what Abraham Maslow calls self-actualization by intuitively engaging in social media interactions. Nobel laureate Daniel Kahneman writes that "intuition is nothing more and nothing less than recognition", is the ability to automatically generate solutions without long logical arguments or evidence [59]. Intuitive is the ability to acquire knowledge without recourse to conscious reasoning [60]. Introspection can reduce the quality of preferences and decisions. Wilson and Schooler's studies demonstrated that analyzing reasons reduces people's satisfaction with their choices, and it may not always be a good idea to analyze the reasons for our preferences too carefully [61].

\subsubsection{Practical Information}

Practical information sharing allows the audience to learn and increase their knowledge, if a post can satisfy users' personal needs and get users' favorites, they will be willing to share this fresh and happy experience, and even feel honored. People naturally seek growth, which Maslow calls self-actualization [31]. Show a tutorial [62] can maintain the user's connection with professionals [44] to make themselves better.

\subsubsection{Asking Questions}

The artist, ranked No.558 has posted only 132 posts in three years, all of which are featured rapid growth of likes and comments by asking questions. The motivation to participate in answering questions is the opportunity for self-expression, in order to receive positive feedback and meet the expectations of others [38]. How to tell a story or how to interact with audience is the key method for success. Artists establish relationships and emotions with followers by asking questions, media researcher Henry Jenkins called it "emotional economy", which is an economic model with extending aesthetic activities [63].

\subsubsection{Curiosity}

Curiosity is heavily associated with all aspects of human development, which derives the process of learning and the desire to acquire knowledge and skills [64]. Curiosity, as a behavior and emotion are attributed over millennia as the driving force behind human development [65]. Kidd says our brains instinctively seek something "just right" for novelty [66]. The brain's "moderate levels of arousal" result in maximum motivation and ultimate success. The optimal-arousal theory attempts to explain this aspect of curiosity by suggesting that one can be motivated to maintain a pleasurable sense of arousal through these exploratory behaviors [65]. When one's curiosity is aroused, it is considered an inner reward and pleasure. The optimal-arousal theory explains social media users' desire to engage in exploratory behavior in uncertain or ambiguous situations. This theory also allows us to understand the desires of social media users in uncertain or ambiguous situations, through "moderate arousal," such as "What is this?" to stimulate people's curiosity and result in more likes.

\subsubsection{Interestingness}

Interestingness is similar to curiosity appeal [67]. Emotions are likely to inform the first impressions of the artwork's aesthetic appeal and interestingness [67]. The arousal potential for emotion is defined as a feeling state of activation that varies from drowsiness to frantic excitement [65]. Emotions and art are intimately related [68], interestingness will enhance a viewer's experience of artwork [69]. Wilson and Schooler's study found that students preferred funny versus artistic posters according to attributes they could verbalize easily, but the preference was reversed when they did not need to explain the 
reason [61]. Aesthetic experience is determined largely by the content and context of the artwork, irrespective of its form [56]. The impression of artwork as thought-provoking and interesting may cause this artwork to be viewed.

\subsubsection{Empathy}

Psychologist Martin Hoffman believes that everyone is born in the capability of feeling empathy [70]. Social media gives the artist building relationships with followers through sharing their art and personal experiences or adventures, these insights into artist life will give followers a sense of connection to the artist. The personal life is like a real-time billboard to eager, watchful eyeballs.

\subsection{Findings of Study 2}

Our analysis of the questionnaire data shows that:

- The most preferred social media platform is Instagram (91\%), and the most used social media for art-related purposes is Instagram $(94 \%)$ too;

- The main motivations of using social media are to share artworks, selling artworks and know more artists;

- $37 \%$ of artists post 5 to 10 posts a week, $46 \%$ of artists are interacting with followers more than 10 times per week;

- $80 \%$ of artists deny that the most-liked artwork is also their favorite artwork;

- $63 \%$ of artists deny that the interaction between the most-liked artwork and followers will influence the creation of their next artwork;

- $63 \%$ of artists did not customize the artwork for their followers.

The male respondents were significantly more likely to customize artworks for their followers $(p<0.05)$ (see Table 6), but there are no differences between males and females regarding the followers number.

Table 6. Customize $t$-test.

\begin{tabular}{|c|c|c|c|c|c|c|c|}
\hline \multicolumn{8}{|c|}{ Group Statistics } \\
\hline & Gender & $N$ & & & $\begin{array}{c}\text { Std. } \\
\text { Deviation }\end{array}$ & Stc & ror Mean \\
\hline \multirow{3}{*}{ Customize } & Male & 15 & & & 0.258 & & .067 \\
\hline & Female & 20 & & & 0.503 & & .112 \\
\hline & & & F & Sig. & $\mathbf{t}$ & df & $\begin{array}{c}\text { Sig. } \\
\text { (Two-Tailed) }\end{array}$ \\
\hline \multirow{2}{*}{ Customize } & \multirow{2}{*}{\multicolumn{2}{|c|}{$\begin{array}{c}\text { Equal variances assumed } \\
\text { Equal variances not } \\
\text { assumed }\end{array}$}} & 40.042 & 0.000 & 3.746 & 33 & 0.001 \\
\hline & & & & & 4.081 & 29.728 & 0.000 \\
\hline
\end{tabular}

\subsection{Discussion 2}

Everyone seeks satisfaction from social media interactions and the act of creation, telling others what you think is important, in order to receive positive feedback and meet others' expectations [38], interactions on social media show a positive view of self [37], develop skills and open up new opportunities [40], to make themselves better [43], this is what Maslow calls self-realization [31].

Some people think social media is killing art, Phil James suggested that Social Media is decimating art and literature [71]. Stephanie Sharlow believes that social media kills creativity, and it is posing a threat to artist [72]. Stephanie Kelly argues that social media is not killing art, but democratizing it [73]. However, the questionnaire survey of artists shows that most artists are loyal to their inner creativity. Male artists seem to be more receptive to customize art for their followers. 


\section{General Discussion}

Social media is all about people, about understanding what triggers people as individuals and in groups, it embedded six persuasive psychological forces, which are reciprocity, social proof, liking, authority, scarcity, and commitment [74]. Social media has democratized the art experience, enabling more people to watch and experience art on their mobile phones. The artist becomes a facilitator of art experience, and the "artwork" becomes an experience created and shared by users [75]. Social media interaction has made citizen curation possible, with citizen curators eliminating the linear didactic relationship between museums and audiences, and exciting new collaborations between professionals and the public. Shoemaker and Vos theorized "gatekeeping" practice as "audience gatekeeping" [76]. Historically, audiences have long been moved out of the art interpretive area via a system of gates and gate-keepers [77]. Today, the audience gatekeepers pass along items and comments based on their own set of criteria to sort out the most-liked artworks we will see.

Interactivity and playfulness are rarely exalted in the conservative institutions, either because they signify a lack of serious comment or because these approaches are populism. Some art managers and artists believe that audiences are under-educated and unprepared, and therefore unable to grasp the nuance of interpretation skills necessary for the meaning and value of a particular artwork [78]. The visual experience of art is complex, arguably includes both cognitive and emotional components $[79,80]$. Perceptual processing is generally faster than cognitive processing. Russell discussed a broad framework that includes perception of the core-affect-altering properties of stimuli, motives, empathy, emotional meta-experience, and affect versus emotion regulation [81]. The neural mechanism responsive to beauty is directly activated by the intrinsic formal properties of the artwork, and the brain processes it automatically and fast. If the gatekeeper determines the artwork we will see, then raises the question about whether the power of the audience gatekeeper will replace thoughtful analysis of the artwork with generalized notions derived from an uncritical, fashion-oriented crowd mentality. What is the future of citizen curators?

Instagram as an image-based online life sharing apps, only allows a quick superficial interaction. People make judgments by intuition in many cases. The bite-sized information can only act as an entry point in the "art experience", and can not substitute for the live experience of seeing the actual "painting" which may be just an illusion.

\section{Limitations and Future Research}

While our study shows many insights, we acknowledge some limitations that can be addressed in future studies. First, we are not talking about social media algorithms, which value directly affects users. Jiajia Fei indicates that if art is led by social media, then the creation of artworks is at the risk of fit the algorithm [2]. Second, visual art is a complex stimulus, and we did not discuss the impact of aesthetic stimuli elements (such as lines, shapes, and colors) on the perceiver. In spite of the limitations, our study represents a step toward a more thorough understanding of how visual arts are perceived and evaluated, helping us better understand the interactions and citizen curation on social media.

Social media is a consumable product that allows people to interact only with a quick superficial with art, whereas visual art is a complex stimulus. Whether the appreciation of art just stays at the perceptual processing, or how much do the most-liked artworks have to do with aesthetic or quality, all deserve further study. Furthermore, the category of visual arts has many subcategories, and future research is likely to focus on the perceptual differences between different categories.

\section{Conclusions}

We conducted an extensive analysis of the interaction between artists and followers through the data set on Instagram to determine the feature of the most-liked artworks and whether the interaction with followers affected the artists' creation. The results indicate that the most-liked artworks are more interactives. The most-liked and most-commented artworks filtered by gatekeepers seem to be based 
on human instinct, as we discussed in study 1 . Self-actualization is the biggest driving force for social media interaction. These findings reveal the shed light on the nature of "like" and the Instagram users' interaction behavior with art, pointing out what kind of post is becoming "popular".

Our work explores a new path to understanding the social aspects of artworks and expanding the research on the interaction of mobile social media in the art world, which is of great significance for the research of the interaction psychology of artwork on social media and digital marketing communication. From an academic perspective, the findings can support future research in the fields of art psychology, citizen curators, and marketing communication areas on social media, as well as improve our understanding of how museums communicate with the public.

Social media has changed the experience of appreciating the image, and it provides many filters and design tools to make our pictures look better. Various artworks are rapidly presented in a "design + photography" way on social media, and interaction becomes very important. Popular culture, such as Instagramism [82] and snapshot aesthetics have produced based on social media. Social media offers a platform not only for studying contemporary art but also for the study of art cultural evolution and dynamics.

Social media interaction has a profound impact on art institutions and audiences, and as media technology continues to update, art experience and participatory culture will continue to change. What cultural resources do the audiences needs to feel that they are interpreters of the meaning and value of art? Importantly, how does the collaboration of audience and experts relate to these resources and techniques in the hermeneutic process? The result may be the emergence of a new social norm.

Author Contributions: Data curation, J.K.; Formal analysis, X.K.; Investigation, X.K.; Methodology, X.K.; Project administration, J.K.; Resources, X.K.; Software, X.K. and J.K.; Supervision, W.C. and J.K.; Writing-original draft, X.K.; Writing_review and editing, W.C. and J.K.

Funding: This research received no external funding.

Conflicts of Interest: The authors declare no conflict of interest.

\section{References}

1. McAndrew, C. The Art Market 2018 An Art Basel \& UBS Report; UBS: Zurich, Switzerland, 2018.

2. Fei, J. Art in the Age of Instagram. Available online: https://www.speeches.io/art-in-the-age-of-instagramjia-jia-fei-tedxmarthasvineyard-with-evaluation-form/ (accessed on 29 October 2019).

3. Hiscox. Hiscox Online Art Trade Report; Hiscox: Hamilton, Bermuda, 2017.

4. Capriotti, P. Museums' communication in small-and medium-sized cities. Corp. Commun. Int. J. 2010, 15, 281-298. [CrossRef]

5. Crenn, G.; Vidal, G. Les Musées Français et Leurs Publics a L'âge du Web 2.0. Nouveaux Usages du Multimédia et Transformations des Rapports Entre Institutions et Usagers; Archives \& Museum Informatics: Toronto, ON, Canada, 2007; pp. 24-26.

6. Gaëlle, C. Les musées français et leurs publics à l'âge du web 2.0. Nouveaux usages du multimédia et transformations des rapports entre institutions et usagers? In Proceedings of the International Cultural Heritage Informatics Meetings, Toronto, ON, Canada, 24-26 October 2007.

7. Sigala, M. A learning assessment of online interpretation practices: From Museum supply chains to experience ecologies. Inf. Commun. Technol. Tour. 2005, 2005, 67-78.

8. Kent, M.L. Critical analysis of blogging in public relations. Public Relat. Rev. 2008, 34, 32-40. [CrossRef]

9. Sokolowsky, J. Art in the Instagram Age: How Social Media Is Shaping Art and How You Experience It. 2017. Available online: https:/www.seattletimes.com/entertainment/visual-arts/art-in-the-instagram-agehow-social-media-is-shaping-art-and-how-you-experience-it/ (accessed on 29 October 2019).

10. Hakanen, E.A. Branding the Teleself: Media Effects Discourse and the Changing Self; Lexington Books: Lanham, MD, USA, 2007.

11. Walmsley, B. From arts marketing to audience enrichment: How digital engagement can deepen and democratize artistic exchange with audiences. Poetics 2016, 58, 66-78. [CrossRef] 
12. Fleming, D. Managing change in museums. In Proceedings of the Museum and Change International Conference, National Museum, Prague, Czech Republic, 8-10 November 2005.

13. Fleming, O. Why the World's Most Talked-About New Art Dealer Is Instagram. Available online: https: //www.vogue.com/article/buying-and-selling-art-on-instagram (accessed on 13 May 2014).

14. Manovich, L. Instagram and Contemporary Image; Manovich. NET: New York, NY, USA, 2017.

15. Proctor, N. Digital: Museum as platform, curator as champion, in the age of social media. Curator Mus. J. 2010, 53, 35-43. [CrossRef]

16. Hart, H. Walker Visitors Vote for Half the Works to View in New Show. 2010. Available online: http: //www.artnews.com/2010/12/01/citizen-curators/ (accessed on 29 October 2019).

17. McLuhan, M. Understanding Media: The Extensions of Man; Marshall McLuhan; MIT Press: Cambridge, MA, USA, 1994.

18. Deighton, J.; Sorrell, M. The future of interactive marketing. Harv. Bus. Rev. 1996, 74, 151-160.

19. Valcanis, T. An iPhone in every hand: Media ecology, communication structures, and the global village. Etc A Rev. Gen. Semant. 2011, 68, 33-45.

20. Jenkins, H. Confronting the Challenges of Participatory Culture: Media Education for the 21st Century; Mit Press: Cambridge, MA, USA, 2009.

21. Manovich, L. Cultural Analytics: Visualising Cultural Patterns in the Era of "More Media"; Domus: March, Italy, 2009.

22. Ding, C.; Cheng, H.K.; Duan, Y.; Jin, Y. The power of the "like" button: The impact of social media on box office. Decis. Support Syst. 2017, 94, 77-84. [CrossRef]

23. Salo, J.; Lankinen, M.; Mäntymäki, M. The use of social media for artist marketing: Music industry perspectives and consumer motivations. Int. J. Media Manag. 2013, 15, 23-41. [CrossRef]

24. Bakhshi, S.; Shamma, D.A.; Kennedy, L.; Gilbert, E. Why we filter our photos and how it impacts engagement. In Proceedings of the Ninth International AAAI Conference on Web and Social Media, Oxford, UK, 26-29 May 2015.

25. Simo-Serra, E.; Fidler, S.; Moreno-Noguer, F.; Urtasun, R. Neuroaesthetics in fashion: Modeling the perception of fashionability. In Proceedings of the IEEE Conference on Computer Vision and Pattern Recognition, Boston, MA, USA, 7-12 June 2015.

26. Segalin, C.; Cheng, D.S.; Cristani, M. Social profiling through image understanding: Personality inference using convolutional neural networks. Comput. Vis. Image Underst. 2017, 156, 34-50. [CrossRef]

27. Sherren, K.; Parkins, J.R.; Smit, M.; Holmlund, M.; Chen, Y. Digital archives, big data and image-based culturomics for social impact assessment: Opportunities and challenges. Environ. Impact Assess. Rev. 2017, 67, 23-30. [CrossRef]

28. Esaak, S. What Are the Visual Arts? 2019. Available online: https://www.thoughtco.com/what-are-thevisual-arts-182706 (accessed on 29 October 2019).

29. Wikipedia. New Media Art. Available online: https://en.wikipedia.org/wiki/New_media_art\#cite_ref-3 (accessed on 29 October 2019).

30. Modell, A.H. The Private Self; Harvard University Press: Cambridge, MA, USA, 1993.

31. Maslow, A.H. Motivation and Personality; Harper \& Row: New York, NY, USA, 1975.

32. Ritter, D. The intersection of art and interactivity. Ars Electron. Festiv. 1996, 96, 274-285.

33. Bowen, J.; Bradburne, J.; Burch, A.; Dierking, L.; Falk, J. Digital Technologies and the Museum Experience: Handheld Guides and Other Media; Rowman Altamira: Lanham, MD, USA, 2008.

34. Kristin, T.; Kristen, P.; Lee, R. Arts Organizations and Digital Technologies. 2013. Available online: http://www.pewinternet.org/2013/01/04/arts-organizations-and-digital-technologies/ (accessed on 29 October 2019).

35. Boyd, D.M.; Ellison, N.B. Social network sites: Definition, history, and scholarship. J. Comput. Mediat. Commun. 2007, 13, 210-230. [CrossRef]

36. Lee, E.; Lee, J.A.; Moon, J.H.; Sung, Y. Pictures speak louder than words: Motivations for using Instagram. Cyberpsychol. Behav. Soc. Netw. 2015, 18, 552-556. [CrossRef] [PubMed]

37. Goffman, E. The Presentation of Self: Goffman Drmaturgical Model; Indiana Press: Bloomington, IN, USA, 1994.

38. Goffman, E. The Presentation of Self in Everyday Life; Harmondsworth: London, UK, 1978.

39. Kim, A.J. Community Building on the Web: Secret Strategies for Successful Online Communities Community; Addison-Wesley Longman Publishing Co., Inc.: Boston, MA, USA, 2000. 
40. Zhu, Y.-Q.; Chen, H.-G. Social media and human need satisfaction: Implications for social media marketing. Bus. Horiz. 2015, 58, 335-345. [CrossRef]

41. Sheldon, K.M.; Elliot, A.J.; Kim, Y.; Kasser, T. What is satisfying about satisfying events? Testing 10 candidate psychological needs. J. Personal. Soc. Psychol. 2001, 80, 325. [CrossRef]

42. Baym, N.K. Connect with your audience! The relational labor of connection. Commun. Rev. 2015, 18, 14-22.

43. Kenneth, O.; Cliff, L.; Nicole, B.E. Social Media and the Workplace. 2017. Available online: http://www. pewinternet.org/2016/06/22/social-media-and-the-workplace/ (accessed on 29 October 2019).

44. Nabi, I.R. Instagram: Motives for its Use and Relationship to Narcissism and Contextual Age; Bahria University Karachi Campus: Karachi, Pakistan, 2017.

45. Hochman, N.; Schwartz, R. Visualizing instagram: Tracing cultural visual rhythms. In Proceedings of the Sixth International AAAI Conference on Weblogs and Social Media, Dublin, Ireland, 4-7 June 2012.

46. You, Q.; García-García, D.; Paluri, M.; Luo, J.; Joo, J. Cultural diffusion and trends in facebook photographs. In Proceedings of the Eleventh International AAAI Conference on Web and Social Media, Montréal, QC, Canada, 15-18 May 2017.

47. Parker, C.J.; Wang, H. Examining hedonic and utilitarian motivations for $\mathrm{m}$-commerce fashion retail app engagement. J. Fash. Mark. Manag. Int. J. 2016, 20, 487-506. [CrossRef]

48. Matzen, K.; Bala, K.; Snavely, N. Streetstyle: Exploring world-wide clothing styles from millions of photos. arXiv 2017, arXiv:1706,01869.

49. Hu, Y.; Manikonda, L.; Kambhampati, S. What we instagram: A first analysis of instagram photo content and user types. In Proceedings of the Eighth International AAAI Conference on Weblogs and Social Media, Ann Arbor, MI, USA, 1-4 June 2014.

50. Hamari, J.; Sjöklint, M.; Ukkonen, A. The sharing economy: Why people participate in collaborative consumption. J. Assoc. Inf. Sci. Technol. 2016, 67, 2047-2059. [CrossRef]

51. Kang, X.; Chen, W. The Like Economy: The Impact of Interaction between Artists and Fans on Social Media in Art Market. In Proceedings of the International Conference on Business and Information Management, Beijing, China, 23-25 July 2017; ACM: Beijing, China, 2017; pp. 45-49.

52. Wikiart. ARTWORKS BY GENRE. Available online: https://www.wikiart.org/en/paintings-by-genre (accessed on 29 October 2019).

53. Bourdieu, P.; Darbel, A. The Love of Art; European Art Museums and their Public, Polity Press: Cambridge, UK, 1991.

54. McCornack, S.; Ortiz, J. Choices E Connections: An Introduction to Communication; Macmillan Higher Education: New York, NY, USA, 2019.

55. Bakhshi, S.; Shamma, D.A.; Gilbert, E. Faces engage us: Photos with faces attract more likes and comments on instagram. In Proceedings of the SIGCHI Conference on Human Factors in Computing Systems, Toronto, ON, Canada, 1-26 April 2014; ACM: New York, NY, USA, 2014.

56. Redies, C. Combining universal beauty and cultural context in a unifying model of visual aesthetic experience. Front. Hum. Neurosci. 2015, 9, 218. [CrossRef] [PubMed]

57. Takeuchi, A.; Nagao, K. Communicative facial displays as a new conversational modality. In Proceedings of the INTERACT'93 and CHI'93 Conference on Human Factors in Computing Systems, Amsterdam, The Netherlands, 24-29 April 1993; ACM: New York, NY, USA, 1993.

58. Goldman, A.I.; Sripada, C.S. Simulationist models of face-based emotion recognition. Cognition 2005, 94, 193-213. [CrossRef] [PubMed]

59. Kahneman, D. Thinking, Fast and Slow; Macmillan: New York, NY, USA, 2011.

60. Merriam Webster. Intuition. Available online: https://www.merriam-webster.com/dictionary/intuition (accessed on 29 October 2019).

61. Wilson, T.D.; Schooler, J.W.; Schooler, J.W. Thinking too much: Introspection can reduce the quality of preferences and decisions. J. Personal. Soc. Psychol. 1991, 60, 181. [CrossRef]

62. Tran, T. What to Post on Instagram: 15 Creative and Engaging Ideas. 2019. Available online: https: //blog.hootsuite.com/instagram-post-ideas/ (accessed on 29 October 2019).

63. Jenkins, H. Interactive Audiences; The New Media Book: London, UK, 2002; pp. 157-170.

64. Zuss, M. The Practice of Theoretical Curiosity; Springer Science \& Business Media: Berlin/Heidelberg, Germany, 2011; Volume 20. 
65. Russell, J.A.; Mehrabian, A. Distinguishing anger and anxiety in terms of emotional response factors. J. Consult. Clin. Psychol. 1974, 42, 79. [CrossRef]

66. Kidd, C.; Piantadosi, S.T.; Aslin, R.N. The Goldilocks effect: Human infants allocate attention to visual sequences that are neither too simple nor too complex. PLoS One 2012, 7, e36399. [CrossRef]

67. Cupchik, G.C.; Gebotys, R.J. Interest and pleasure as dimensions of aesthetic response. Empir. Stud. Arts 1990, 8, 1-14. [CrossRef]

68. Tan, E.S. Emotion, art, and the humanities. Handb. Emot. 2000, 3, 116-134.

69. Hagtvedt, H.; Patrick, V.M.; Hagtvedt, R. The perception and evaluation of visual art. Empir. Stud. Arts 2008, 26, 197-218. [CrossRef]

70. Roth-Hanania, R.; Davidov, M.; Zahn-Waxler, C. Empathy development from 8 to 16 months: Early signs of concern for others. Infant Behav. Dev. 2011, 34, 447-458. [CrossRef]

71. James, P. 8 Reasons Why Social Media is Decimating Art and Literature. 2014. Available online: https://qwiklit.com/2014/03/08/8-reasons-why-social-media-is-decimating-art-and-literature/ (accessed on 29 October 2019).

72. Sharlow, S. Death of An Artist: How Social Media Is Ruining Creativity. 2015. Available online: https: //www.elitedaily.com/life/culture/death-artist-social-media-ruining-creativity/907113 (accessed on 29 October 2019).

73. Whitehead, K. Is Social Media Killing Art or Bringing it to the People? Available online: https://www.scmp. com/culture/arts-entertainment/article/2074306/social-media-killing-art-or-bringing-it-people (accessed on 28 Feburary 2017).

74. Maharani, N.; Sevriana, L. Analysis of Attitude, Motivation, Knowledge and Lifestyle of the Consumers in Bandung Who Shop through Instagram. Winners 2017, 18, 13-23. [CrossRef]

75. Polaine, A. Lowbrow, high art: Why Big Fine Art doesn't Understand Interactivity. Available online: http://p102.donau-uni.ac.at/xmlui/handle/10002/563. (accessed on 29 October 2019).

76. Shoemaker, P.J.; Vos, T. Gatekeeping Theory; Routledge: Abingdon, UK, 2009.

77. Lewin, K. Forces behind food habits and methods of change. Bull. Natl. Res. Counc. 1943, 108, 35-65.

78. Conner, L. Taking Back the Arts: 21st Century Audiences, Participatory Culture and the End of Passive Spectatorship. L'ordinaire Des Amériques 2016, 220. [CrossRef]

79. Baltissen, R.; Ostermann, B.-M. Are the dimensions underlying aesthetic and affective judgment the same? Empir. Stud. Arts 1998, 16, 97-113. [CrossRef]

80. Silvia, P.J. Emotional responses to art: From collation and arousal to cognition and emotion. Rev. Gen. Psychol. 2005, 9, 342-357. [CrossRef]

81. Russell, J.A. Core affect and the psychological construction of emotion. Psychol. Rev. 2003, 110, 145. [CrossRef] [PubMed]

82. Manovich, L. Notes on Instagrammism and Mechanisms of Contemporary Cultural Identity (and Also Photography, Design, Kinfolk, k-pop, Hashtags, Mise-en-Scène, and Состояние). 2016. Available online: http://manovich.net/index.php/projects/instagram-and-contemporary-image (accessed on 29 October 2019).

(C) 2019 by the authors. Licensee MDPI, Basel, Switzerland. This article is an open access article distributed under the terms and conditions of the Creative Commons Attribution (CC BY) license (http://creativecommons.org/licenses/by/4.0/). 